\title{
Comparison of Efficacy in Abnormal Cervical Cell Detection between Liquid-based Cytology and Conventional Cytology
}

\author{
Jitraporn Tanabodee ${ }^{1 *}$, Kitisak Thepsuwan ${ }^{1}$, Anant Karalak ${ }^{2}$, Orawan Laoaree ${ }^{1}$, \\ Anong Krachang ${ }^{1}$, Kittipong Manmatt ${ }^{1}$, Nualpan Anontwatanawong ${ }^{1}$
}

\begin{abstract}
This study was conducted to 1206 women who had cervical cancer screening at Chonburi Cancer Hospital. The spilt-sample study aimed to compare the efficacy of abnormal cervical cells detection between liquid-based cytology (LBC) and conventional cytology (CC). The collection of cervical cells was performed by broom and directly smeared on a glass slide for $\mathrm{CC}$ then the rest of specimen was prepared for LBC. All slides were evaluated and classified by The Bethesda System. The results of the two cytological tests were compared to the gold standard. The LBC smear significantly decreased inflammatory cell and thick smear on slides. These two techniques were not difference in detection rate of abnormal cytology and had high cytological diagnostic agreement of $95.7 \%$. The histologic diagnosis of cervical tissue was used as the gold standard in 103 cases. Sensitivity, specificity, positive predictive value, negative predictive value, false positive, false negative and accuracy of LBC at ASC-US cut off were 81.4, 75.0, 70.0, 84.9, 25.0, 18.6 and 77.7\%, respectively. $\mathrm{CC}$ had higher false positive and false negative than LBC. LBC had shown higher sensitivity, specificity, PPV, NPV and accuracy than CC but no statistical significance. In conclusion, LBC method can improve specimen quality, more sensitive, specific and accurate at ASC-US cut off and as effective as $\mathrm{CC}$ in detecting cervical epithelial cell abnormalities.
\end{abstract}

Keywords: Liquid-based cytology - conventional cytology - accuracy - sensitivity - specificity

Asian Pac J Cancer Prev, 16 (16), 7381-7384

\section{Introduction}

It is well known that cervical cancer is the second most common cancer affecting women after breast cancer in Thailand. Cervical cancer age-standardized incidence rate is 16.7 in 2007-2009 (Khuhaprema et al., 2013). As known, the goal for cervical cancer screening program is to reduce invasive cervical cancer. The incidence of cervical cancer did not reduce satisfactory due to insufficient screening.

Evidence has shown that cervical cytology can increase detect rate of precancerous lesion. Conventional Pap smear has been used in Thailand national cervical cancer screening policy. A systemic review demonstrated that the sensitivity and specificity of conventional cytology (CC) range from 79 to $100 \%$ (mean 95\%) and 30 to $80 \%$ (mean 47\%), respectively (Nanda et al., 2000). It is widely acknowledged that two thirds of the overall falsenegative rate of CC can be attributed to sampling errors. There are two major components to sampling errors: clinician derived, in which the representative diagnostic cells simply are not collected by the device, and sample preparation derived, in which the representative cells on the collection device are not transferred to the slide. To overcome these problems, liquid-based cytology (LBC), the new collection device and the monolayer or thin-layer system, has been used for cervicovaginal smear.

Many reports have shown the superiority of LBC over CC (Roberts et al., 1997, Austin et al., 1998, Corkill et al., 1998, Fremont-Smith et al., 2004). LBC was approved by the United States Food and Drug Administration for use in the primary screening of cervical specimens. Nowadays, a number of different LBC techniques are available in Thailand, but it is not widely available and still costly. We use Pathtezt ${ }^{\mathrm{TM}}$ because it has never been tested for the accuracy, sensitivity, and specificity compared to the CC.

To evaluate effectiveness of LBC cervical screening test, we compared the efficacy of abnormal epithelial cells detection and quality of smears of LBC to CC.

\section{Materials and Methods}

From November 2012 to December 2013, the crosssectional study was performed at Gynecologic Outpatient Unit, Cytology Unit, Chonburi Cancer Hospital (CCH) and Department of pathology, National Cancer Institute (NCI).

Women between 25 and 65 years old who attended for pelvic examination or cervical cancer screening program, gave written informed consent after reviewing a summary of this study plan. Women who had previously undergone any cervical surgical procedures, were pregnant, used any 
Jitraporn Tanabodee et al

kinds of vaginal preparations or pelvic examination within previous 48 hours were excluded. Endo-ectocervical cell was collected by rotating 5 times in the same direction with cervical broom. This is the split-sample, matchedpair study. After directly smearing cell onto a single glass slide for $\mathrm{CC}$, the leftover cell on broom was rinsed into a vial of specific preservative solution. The CC slides were immediately immersed in $95 \%$ ethanol for fixation. The LBC vials were processed by a semi-automated sample preparation instrument. A rotary drive mechanism gently disperses samples. A Pneumatic/Fluidic system was controlled by a microprocessor, monitored cell collection. After the cells are collected on the exterior surface of the membrane, the filter is inverted and gently pressed against the PathTeztTM Microscope Slide. Natural attraction and slight positive air pressure cause the cell to adhere to the slide resulting in an even distribution of cells in a defined circular area. The slides from both techniques were prepared, screened, interpreted by two cytotechnologists at $\mathrm{CCH}$ and the results were confirmed by pathologist at NCI using the Bethesda 2001 system. The interpretations of the results from one technique were made without knowledge of those from the other technique. Abnormal cytology was defined as atypical squamous cells of undetermined significance (ASCUS) or higher.

The women who had abnormal cytology would undergo colposcopically directed cervical biopsy and/ or endocervical curettage. Then some treatments were performed later (loop electrosurgical excision procedure, conization and hysterectomy). Hysterectomy was performed in some normal cytological women due to other gynecologic indication not cancer i.e. leiomyoma, endometriotic cyst. The tissues were transported to NCI for pathological diagnosis that was used as the gold standard. This study used the worst histological results.

The results from both techniques were compared quality of slide, accuracy, sensitivity and specificity. Data were analyzed using PASW Statistics 18. Test for difference by McNemar's test. In all tests, results with P-value of less than 0.05 were considered statistically significant.

\section{Results and Discussion}

There were 1206 women recruited during the study period. Table 1 demonstrates the comparison of quality and quantity of CC and LBC. There is no difference of squamous metaplasia cell and endocervical cell in both techniques. The LBC significantly decreased RBC, WBC, mucous and thick smear on slides. This results in the decrease of unsatisfactory smear incidence. Bishop et al (1998) showed more than $15 \%$ of slide by Pap smear is obscured by RBC, WBC, mucous and thick smear that relate to false negative results.

The comparison of cytological diagnoses between $\mathrm{CC}$ and LBS showed that the cytological diagnoses from both techniques agreed exactly in 1154 of the 1206 women (95.7\%) and the detection rate of abnormal cytology in both techniques is not different. In this study we chose the spilt-sample study so it is difficult to ensure that the both cytology specimens are comparable, because the
Table 1. Comparison of Quality and Quantity between CC and LBC in 1206 Pairs of Samples

\begin{tabular}{|c|c|c|c|}
\hline \multicolumn{2}{|c|}{ Results } & $\mathrm{CC}(\mathrm{N}(\%))$ & $\mathrm{LBC}(\mathrm{N}(\%))$ \\
\hline \multicolumn{2}{|c|}{$\begin{array}{l}\text { Presence of transformation } \\
\text { zone component }\end{array}$} & $1167(96.8 \%)$ & $1183(98.1 \%)$ \\
\hline \multirow{3}{*}{$\begin{array}{l}\text { Squamous } \\
\text { metaplasia } \\
\text { cell }\end{array}$} & 0 cell & $126(10.4 \%)$ & $99(8.2 \%)$ \\
\hline & $1-9$ cell & $126(10.4 \%)$ & $128(10.6 \%)$ \\
\hline & $>10$ cell & $954(79.1 \%)$ & $979(81.2 \%)$ \\
\hline \multirow{4}{*}{$\begin{array}{l}\text { Endocervical } \\
\text { cell }\end{array}$} & 0 cell & $100(8.3 \%)$ & $51(4.2 \%)$ \\
\hline & $1-5$ cell & $198(16.4 \%)$ & $166(13.8 \%)$ \\
\hline & 6-10 cell & $147(12.2 \%)$ & $145(12.0 \%)$ \\
\hline & $>10$ cell & $761(63.1 \%)$ & $844(70.0 \%)$ \\
\hline \multirow{3}{*}{ Obscuration } & $<50 \%$ & $227(18.8 \%)$ & $1161(96.3 \%) *$ \\
\hline & $50-75 \%$ & $843(69.9 \%)$ & $42(3.5 \%) *$ \\
\hline & $>75 \%$ & $136(11.3 \%)$ & $3(0.2 \%)^{*}$ \\
\hline \multirow{4}{*}{$\begin{array}{l}\text { Obscured } \\
\text { factors }\end{array}$} & $\mathrm{RBC}$ & $114(9.5 \%)$ & $1(0.1 \%)^{*}$ \\
\hline & WBC & $474(39.3 \%)$ & $3(0.2 \%)^{*}$ \\
\hline & mucous & $741(61.4 \%)$ & $8(0.7 \%)^{*}$ \\
\hline & thickness & $824(68.3 \%)$ & $43(3.6 \%)^{*}$ \\
\hline
\end{tabular}

$\mathrm{RBC}=$ red blood cell, $\mathrm{WBC}=$ white blood cell, $* \mathrm{P}<0.001$

Table 2. Detection Rates of Abnormal Cervical Cytology between $\mathrm{CC}$ and $\mathrm{LBC}$

\begin{tabular}{lcc}
\hline Finding & $\mathrm{CC}(\mathrm{N}(\%))$ & $\mathrm{LBC}(\mathrm{N}(\%))$ \\
\hline ASC-US & $15(1.2)$ & $14(1.2)$ \\
LSIL & $16(1.3)$ & $18(1.5)$ \\
HSIL & $5(0.4)$ & $4(0.3)$ \\
AGC & $3(0.3)$ & $3(0.3)$ \\
AIS & $2(0.2)$ & 0 \\
Cancer & $13(1.1)$ & $11(0.9)$ \\
Overall & $54(4.5)$ & $50(4.1)$ \\
\hline
\end{tabular}

*ASC-US= atypical squamous cells of undetermined significance, $\mathrm{LSIL}=$ low-grade squamous intraepithelial lesion, HSIL= high-grade squamous intraepithelial lesion, $\mathrm{AGC}=$ atypical glandular cells not otherwise specified, AIS $=$ Adenocarcinoma in situ

Table 3. Comparison of Cytological Diagnoses between $\mathrm{CC}$ and $\mathrm{LBC}$ in 1206 Pairs of Samples

\begin{tabular}{lrrrrrr}
\hline Conventional Cytology & \multicolumn{5}{c}{ LBC(number) } \\
\cline { 2 - 7 } & Negative/BCC & ASC-US & LSIL & HSIL & AGC & Cancer \\
\hline Negative/BCC & 1129 & 14 & 8 & 1 & 0 & 0 \\
ASC-US & 15 & 0 & 0 & 0 & 0 & 0 \\
LSIL & 6 & 0 & 10 & 0 & 0 & 0 \\
HSIL & 3 & 0 & 0 & 2 & 0 & 0 \\
AGC & 1 & 0 & 0 & 0 & 2 & 0 \\
AIS & 2 & 0 & 0 & 0 & 0 & 0 \\
Cancer & 0 & 0 & 0 & 1 & 1 & 11 \\
\hline
\end{tabular}

$\mathrm{BCC}=$ benign cellular change

specimen for CC slide is collected before the specimen for LBC. Weintraub and Morabia (2000) study showed the $\mathrm{LBC}$ is more effective than $\mathrm{CC}$ for detecting epithelial cell abnormalities in split-sample design and direct to vial design. LBC sample quality is better. A randomized controlled trial has shown that the detection rate of abnormal epithelium at ASC-US and higher on LBC and $\mathrm{CC}$ is not different. However, $\mathrm{LBC}$ has less unsatisfactory 
Table 4. Correlation of Histologic and Cytological Diagnoses on CC and LBC ( $N=103)$

\begin{tabular}{lcccc}
\hline Cytological Result & \multicolumn{3}{c}{ Histologic Diagnoses (Number) } \\
\cline { 2 - 5 } & Normal/Cervicitis & CIN 1/HPV & CIN 2-3/CIS & Cancer \\
\hline CC & 39 & 7 & 3 & 0 \\
Negative/BCC & 10 & 5 & 0 & 0 \\
ASC-US & 5 & 11 & 0 & 0 \\
LSIL & 3 & 0 & 2 & 0 \\
HSIL & 1 & 0 & 0 & 0 \\
AGC & 2 & 0 & 0 & 12 \\
AIS & 0 & 0 & 1 & 0 \\
Cancer & & & 0 & 0 \\
LBC & 45 & 8 & 2 & 0 \\
Negative/BCC & 8 & 4 & 0 & 3 \\
ASC-US & 7 & 11 & 4 & 0 \\
LSIL & 0 & 0 & 0 & 0 \\
HSIL & 0 & 0 & 0 & 11 \\
AGC & 0 & 0 & 0 & 0 \\
Cancer & & 0 & \\
\hline
\end{tabular}

$\mathrm{CIN}=$ cervical intraepithelial neoplasia, $\mathrm{HPV}=$ human papilloma virus, $\mathrm{CIS}=$ squamous cell carcinoma in situ

Table 5. Comparison of efficacy between CC and LBC at ASC-US cut off

\begin{tabular}{|c|c|c|c|c|c|}
\hline Test & CC $(\%)$ & CC-CI $(\%)$ & LBC $(\%)$ & LBC-CI (\%) & P-value \\
\hline Sensitivity & 76.7 & $(64.1-89.4)$ & 81.4 & $(69.8-93.0)$ & 0.298 \\
\hline Specificity & 65.0 & $(52.9-77.1)$ & 75.0 & $(64.0-86.0)$ & 0.116 \\
\hline PPV & 61.1 & $(48.1-74.1)$ & 70.0 & $(57.3-82.7)$ & 0.171 \\
\hline NPV & 79.6 & $(68.3-90.9)$ & 84.9 & $(75.3-94.5)$ & 0.241 \\
\hline FP & 35.0 & $(22.9-47.1)$ & 25.0 & $(14.0-40.0)$ & 0.884 \\
\hline FN & 23.3 & $(10.6-35.9)$ & 18.6 & $(7.0-30.2)$ & 0.702 \\
\hline Accuracy & 70.0 & $(61.0-78.8)$ & 77.7 & $(69.6-85.7)$ & 0.102 \\
\hline
\end{tabular}

$\mathrm{PPV}=$ positive predictive value, $\mathrm{NPV}=$ negative predictive value, $\mathrm{FP}=$ false positive rate, $\mathrm{FN}=$ false negative rate, $\mathrm{CI}=95 \%$ Confidence Interval

smear than CC (Sieber et al., 2008).

Table 4 shows the correlation of histologic and cytological diagnoses for each technique in 103 women. 2 AIS, 1 AGC and 3 HSIL women by CC is negative by histology may be due to contaminate with abnormal cell from other slide or missed interpretation on obscured cell, Thus CC false positive is higher than LBC as shown in Table 5. False negative is important. Three women with CIN II-III by histology are negative finding by CC that may be associated with thick smear, obscure factor, and inadequate transfer of the cell onto the slide or the abnormal cell detached from slide in fixation process.

Table 5 shows the sensitivity and specificity of the histologic and cytological results for $\mathrm{CC}$ and $\mathrm{LBC}$ at ASC-US cut off and the comparison of efficacy. CC false positive and false negative are higher than LBC. LBC has shown higher sensitivity, specificity, PPV, NPV and accuracy but no statistical significance. Our LBC result is different from the Siriraj-LBC. The study showed that the Siriraj-LBC increase detection rate of abnormal cervicovaginal cells. This probably caused by decrease false negative but increase false positive from the baseline value by CC. Siriraj-LBC reveal a PPV of $71.1 \%$ and a NPV of $42.2 \%$ (Laiwejpithaya et al., 2008). Our result was compatible with many previous reports. ThinPrep-
LBC (TP) and the CC sensitivity, specificity, PPV and NPV at LSIL cut off were 82.8, 83.0, 88.9, 74.6\%, respectively and $89.6,69.8,83.0,80.4 \%$, respectively. TP was significantly more specific for diagnosing lesion than CC. The sensitivity of the two methods was equivalent (Park et al., 2000). Arunratsamee and Siwadune (2012) evaluated the efficacy between LBC and Pap. Accuracy, sensitivity, specificity, PPV and NPV of Cytoneph-LBC and Pap, when using ASC-US as cut off were 76.4, 87.5, $56.7,59.8,86.0 \%$, respectively and 70.7,90.4, 37.7, 51.6, $84.3 \%$, respectively. The study found no difference in diagnostic performance on both methods. A systemic review and meta-analysis study showed there was not a significant difference in specificity and sensitivity between LBC and CC (Arbyn et al., 2008.

In this study, not all of the study population undergoes the gold standard test. The efficacy parameters were the represent of 103 women who has pathologic results to compare to the new tool. The screening test with higher sensitivity, specificity and cheaper should be used for cervical cancer screening. Larger studies to evaluate the real efficacy parameters and cost-effective analysis of this LBC test is required to improve cervical cancer screening program in Thailand.

In conclusion Pathtezt ${ }^{\mathrm{TM}}$ LBC method can improve 
Jitraporn Tanabodee et al

specimen quality in a thin layer with relatively free of inflammatory cells and clean background. LBC has shown higher sensitivity, specificity and accuracy at ASC-US cut off in our setting. Therefore the screening performance of LBC is not inferior to the Conventional Pap smear and may be used as an alternative screening method for cervical cancer.

\section{Acknowledgements}

The present study was approved by the Ethical Committee on Research Involving Human Subjects, Chonburi Cancer Hospital. The authors wish to thank Mrs.Pimonwan Promsuwan, Ms. Jutathip punworn, Ms. watchara Bounpeth, Ms Sinjai Santhong and Ms. Pitcharee Yimsomboon and all outpatient department staff for cooperate the patients and collecting data and Dr. Yuwadee Leelalukanawera for data analysis. Finally, special thank the patients who participated in this study.

\section{References}

Arbyn M, Bergeron C, Klinkhamer P, et al (2008). Liquid compared with conventional cervical cytology: a systemic review and meta-analysis. Obstet Gynecol, 111, 167-77.

Arunratsamee P, Siwadune T (2012). Comparison of diagnostic efficacy between cytoneph liquid-based cytology and conventional pap smear cytology in colposcopic clinic at chonburi hospital. Thai J Obstet Gynaecol, 20, 41-7.

Austin RM, Ramzy I (1998). Increased detection of epithelial cell abnormalities by liquid-based gynecologic cytology preparations: A review of accumulated data. Acta Cytol, 42, 178-84.

Bishop JW, Bigner SH, Colgan TJ, et al (1998). Multicenter masked evaluate of AutoCyte PREP thin layers with matched conventional smear. Including Initial biopsy results. Acta Cytol, 42, 189-97.

Corkill M, Knapp D, Hutchinson ML (1998). Improved accuracy for cervical cytology with the ThinPrep method and the endocervical brush-spatula collection procedure. J Lower Genital Tract Dis, 2, 12-6.

Fremont-Smith M, Marino J, Griffin B, et al (2004). Comparison of the SurePath liquid-based Papanicolaou smear with the conventional Papanicolaou smear in a multisite direct-to-vial study. Cancer, 102, 269-79.

Khuhaprema T, Attasara P, Sriplung H, et al (2013). Cancer in Thailand 2007-2009. Bangkok, Thailand: National Cancer Institute, 47-50.

Laiwejpithaya S, Rattanachaiyanont M, Benjapibal M, et al (2008). Comparison between Siriraj liquid-based and conventional cytology for detection of abnormal cervicovaginal smear: a split-sample study. Asian Pac J Cancer Prev, 9, 575-80.

Nanda K, McCrory DC, Myers ER, et al (2000). Accuracy of the Papanicolaou test in screening for and follow-up of cervical cytologic abnormalities: a systemic review. Ann Intern Med, 132, 810-9.

Park IA, Lee SN, Chae SW, et al (2001). Comparing the accuracy of thinprep pap tests and conventional papanicolaou smears on the basis of the histologic diagnosis: a clinical study of women with cervical abnormalities. Acta Cytol, 45, 525-31.

Roberts JM, Gurley AM, Thurloe JK, et al (1997). Evaluation of the ThinPrep Pap test as an adjunct to the conventional Pap smear. Med J Aust, 167, 466-9.

Sieber AG, Klinkhamer PJ, Arbyn M, et al (2008). Cytologic detection of cervical abnormalities using liquid-based compared with conventional cytology: a randomized controlled trial. Obstet Gynecol, 112, 1327-34.

Weintraub J, Morabia A (2000). Efficacy of a liquid-based thin layer method for cervical cancer screening in a population with a low incidence of cervical cancer. Diagn Cytopathol, 22, 52-9. 